\title{
Clinical trial of deglycyrrhizinised liquorice in gastric ulcer
}

\author{
K. D. BARDHAN, D. C. CUMBERLAND, R. A. DIXON, AND \\ C. D. HOLDSWORTH ${ }^{1}$
}

From the Departments of Community Medicine, Gastroenterology and Radiology, University of Sheffield, and the Hospitals of the Sheffield Area Health Authority (Teaching) and Rotherham Area Health Authority

SUMMARY Ninety-six patients with gastric ulcer were randomly allocated to treatment either with deglycyrrhizinised liquorice or placebo. After four weeks no differences were found between the treatment groups in the proportions with complete healing, whether assessed by gastroscopy or radiology, or in the percentage reduction in ulcer area, or in clinical improvement.

Liquorice extract from which glycyrrhizinic acid has been removed has been explored as a less toxic alternative to carbenoxolone sodium in the treatment of gastric ulcer. Authors of four papers published between 1968 and 1972 claimed acceleration of gastric ulcer healing comparable with that produced by carbenoxolone sodium and without side effects(Table 1), but the largest treatment group in any of these trials contained only 16 patients and not all trials were double blind. One rather larger trial failed to confirm a beneficial effect (Engqvist et al., 1973).

\section{Method}

All patients had a benign-looking gastric ulcer, verified by endoscopy on entry to the trial. Radiographs were taken showing the ulcer in maximum profile. Ulcer areas in $\mathrm{mm}^{2}$ were standardised against

${ }^{1}$ Address for correspondence: Dr C. D. Holdsworth, Clinical Research Institute, The Royal Infirmary, Sheffield S6 3DA.

Received for publication 29 March 1978 the apparent radiographic size of a one penny piece placed beneath the patient, thereby correcting for the variable magnification effect arising from the tubefilm distance associated with the height of the image intensifier.

Physical examination and blood tests were done within 24 hours of the admission endoscopy. Patients were then randomly allocated under doubleblind conditions, and stratifying for age, sex, and the presence or absence of either cardiovascular disease or hypertension, to take two capsules five times daily for four weeks, containing either $500 \mathrm{mg}$ deglycyrrhizinised liquorice ${ }^{2}$ (DGL) or $200 \mathrm{mg}$ sucrose.

Measured amounts of antacid tablets ${ }^{3}$ and mix-

2Ulcedal, prepared by Cedona of Holland and marketed by Boehringer Ingelheim.

${ }^{3}$ Neutralactis, Wander: dried aluminium hydroxide gel BP $140 \mathrm{mg}$, magnesium trisilicate BP $200 \mathrm{mg}$, calcium carbonate BP $280 \mathrm{mg}$, high protein milk solids $1.5 \mathrm{~g}$.

Table 1 Cumulative experience in five previous trials

\begin{tabular}{|c|c|c|c|c|c|c|}
\hline \multirow[t]{2}{*}{ Treatment group } & \multirow{2}{*}{$\begin{array}{l}\text { Radiological } \\
\text { assessment }\end{array}$} & \multicolumn{5}{|c|}{ Number of patients } \\
\hline & & $\begin{array}{l}\text { Tewariand } \\
\text { Trembalowicz } \\
(1968)\end{array}$ & $\begin{array}{l}\text { Russell and } \\
\text { Dickie } \\
\text { (1968) }\end{array}$ & $\begin{array}{l}\text { Turpie et al. } \\
\text { (1969) }\end{array}$ & $\begin{array}{l}\text { Montgomery and } \\
\text { Cookson } \\
(1972)\end{array}$ & $\begin{array}{l}\text { Engqvist et al. } \\
(1973)^{*}\end{array}$ \\
\hline Deglycyrrizinised liquorice & $\begin{array}{l}\text { Healed } \\
\text { Not healed } \\
\text { Total }\end{array}$ & $\begin{array}{l}5 \\
1 \\
6\end{array}$ & $\begin{array}{l}5 \\
3 \\
8\end{array}$ & $\begin{array}{r}7 \\
9 \\
16\end{array}$ & $\begin{array}{r}6 \\
10 \\
16\end{array}$ & $\begin{array}{r}4 \\
16 \\
20\end{array}$ \\
\hline Placebo & $\begin{array}{l}\text { Healed } \\
\text { Not healed } \\
\text { Total }\end{array}$ & $\begin{array}{l}0 \\
3 \dagger \\
3\end{array}$ & $\begin{array}{l}0 \\
8 \\
8\end{array}$ & $\begin{array}{r}1 \\
16 \\
17\end{array}$ & $\begin{array}{r}4 \\
12 \\
16\end{array}$ & $\begin{array}{l}4 \ddagger \\
14 \\
18\end{array}$ \\
\hline
\end{tabular}

*Results only for first four-week period shown; results similar for second (crossed-over) period.

+First period of a cross-over trial, so these patients included, during second period, in the six DGL patients.

$\ddagger$ Text says five patients, but their last row of Table IV indicates only four. 
ture $^{4}$ were supplied and patients recorded daily their consumption of each type, and any pain experienced. They otherwise continued with normal domestic, dietary, and smoking habits.

At the end of four weeks, the physical examination, blood testing, gastroscopy, and (in most cases) barium meal were repeated, usually all within a 24hour period. Residual capsules and antacid supplies were collected, having been issued in excess of required amounts so that compliance could be checked.

Ulcer healing on gastroscopy was defined as reepithelialisation with or without a scar; the radiological definition was disappearance of the crater.

\section{Results}

Of the total 96 patients, 59 had a single ulcer of at least $10 \mathrm{~mm}^{2}$ seen on barium meal; these form the main study and are presented separately in Tables 2 , 3 , and 4. The remaining 37 had smaller or multiple ulcers or, in a few cases, no initial radiology.

The 48 patients on DGL were similar in age distribution, proportion of males, site of ulcer, and cigarette smoking habits to the 48 on placebo (Table 2). The groups also had similar durations of symptoms and of proportions with epigastric tenderness and with congestive failure or ischaemic heart disease.

${ }^{4}$ Aluminium hydroxide gel BP $280 \mathrm{mg}$, magnesium trisilicate BP $200 \mathrm{mg}$, calcium carbonate $280 \mathrm{mg}$.
However, those on DGL included a smaller proportion of patients with either very large or very small ulcers initially than those on the placebo.

Of the 29 patients on DGL in the main study, six showed healing radiologically at the end of the trial (Table 3); 27 were assessed gastroscopically and 14 showed healing. Similar healing rates by the respective techniques were found among the 30 patients on placebo in the main study. The extent of concordance between the gastroscopic and radiological assessment of healing is the subject of a separate paper (Bardhan et al. (in preparation)). The median percentage change in the ulcer area was again comparable for the two treatment groups; the mean percentage change in ulcer area is shown only for comparison with previous ulcer healing studies. Among the patients not in the main study, few were assessed radiologically at the end of therapy, but gastroscopies were done for most: the proportions healed gastroscopically were the same in those on DGL as in those on placebo.

For each treatment group, healing rates appeared to be higher for ulcers in the body and/or fundus than for other sites (Table 3). For the main study, combining the treatment groups, the difference among the three sites shown was not quite significant at the $5 \%$ level $\left(\chi^{2}=4.2\right.$ with Yates' correction; $\left.2 \mathrm{df}\right)$, while the difference between the body and/or fundus compared with the other two sites combined was significant at this level $\left(\chi^{2}=4.7 ; 1 \mathrm{df}\right)$. Similar conclusions obtain if the data for all 95 patients for whom the site was known are used.

Table 2 Comparability of treatment groups on admission

\begin{tabular}{|c|c|c|c|c|c|c|}
\hline & \multicolumn{4}{|c|}{ Initially seen both by radiology and gastroscopy } & \multicolumn{2}{|c|}{ All patients* } \\
\hline & \multicolumn{2}{|c|}{$\begin{array}{l}\text { Single ulcers initially } \\
\geqslant 10 \mathrm{~mm}^{2}\end{array}$} & \multirow{2}{*}{\multicolumn{2}{|c|}{$\begin{array}{l}\text { Small ulcers initially } \\
<10 \mathrm{~mm}^{2}, \text { and } / o r \\
\text { multiple ulcers }\end{array}$}} & \multirow[t]{3}{*}{$D G L$} & \multirow[t]{3}{*}{ Placebo } \\
\hline & \multirow{2}{*}{$D G L$} & \multirow{2}{*}{ Placebo } & & & & \\
\hline & & & $D G L$ & Placebo & & \\
\hline \multicolumn{7}{|l|}{ Sex } \\
\hline Males & 20 & 17 & 9 & 10 & 33 & 28 \\
\hline Females & 9 & 13 & 3 & 4 & 15 & 20 \\
\hline \multicolumn{7}{|l|}{ Age (yr) } \\
\hline Mean & $54 \cdot 1$ & $53 \cdot 4$ & $51 \cdot 8$ & $53 \cdot 7$ & $54 \cdot 3$ & $54 \cdot 3$ \\
\hline \multicolumn{7}{|l|}{ Ulcer area } \\
\hline Median ulcer area $\left(\mathrm{mm}^{2}\right)$ & $26 \cdot 5$ & $35 \cdot 6$ & $10 \cdot 1$ & $7 \cdot 1$ & $21 \cdot 3$ & $22 \cdot 1$ \\
\hline No. with small ulcers $\left(<10 \mathrm{~mm}^{2}\right)$ & - & - & 6 & 12 & 10 & 14 \\
\hline No. with large ulcers $\left(\geqslant 100 \mathrm{~mm}^{2}\right)$ & 1 & 7 & - & - & 1 & 7 \\
\hline Multiple & 一 & 一 & 6 & 2 & 6 & 2 \\
\hline \multicolumn{7}{|l|}{ Ulcer site } \\
\hline Pre-pyloric/antrum & 4 & 6 & 2 & 3 & 8 & 10 \\
\hline$\leqslant 2 \mathrm{~cm}$ from incisura & 9 & 5 & 1 & 1 & 11 & 6 \\
\hline Body and/or fundus & 16 & 19 & 9 & 10 & 29 & 30 \\
\hline Not recorded & - & 一 & - & - & - & 2 \\
\hline \multicolumn{7}{|l|}{ Smoking } \\
\hline 10 or more cigarettes daily & 19 & 14 & 5 & 9 & 29 & 24 \\
\hline Total no. of patients & 29 & 30 & 12 & 14 & 48 & 48 \\
\hline
\end{tabular}

Numbers of patients unless otherwise stated.

*Including 11 patients assessed gastroscopically only, or for whom initial ulcer size not known. 
A similar proportion in each treatment group experienced improvement in dyspepsia/abdominal pain and in epigastric tenderness (Table 4). As some patients failed to complete their daily records, results are shown only for those patients who entered positive or negative data on at least 24 days, for daytime pain, antacid tablets, and antacid mixture respectively; the treatment groups did not differ significantly in any of these items (Wilcoxon's rank sum tests), for the main study or for the remaining patients.
On the basis of the pharmacists' count of returned capsules, mean total consumption among 46 patients on DGL returning their bottles was 262 (SD 23) and among 44 patients on placebo was also 262 (SD 27): consumption over 28 days should have been 280 . Smoking and drinking habits during treatment as determined from the daily records continued much as before treatment.

A possible side-effect was noted in only one patient who became oedematous and developed hypokalaemia while taking DGL, although her weight

Table 3 Ulcer healing at end of trial therapy

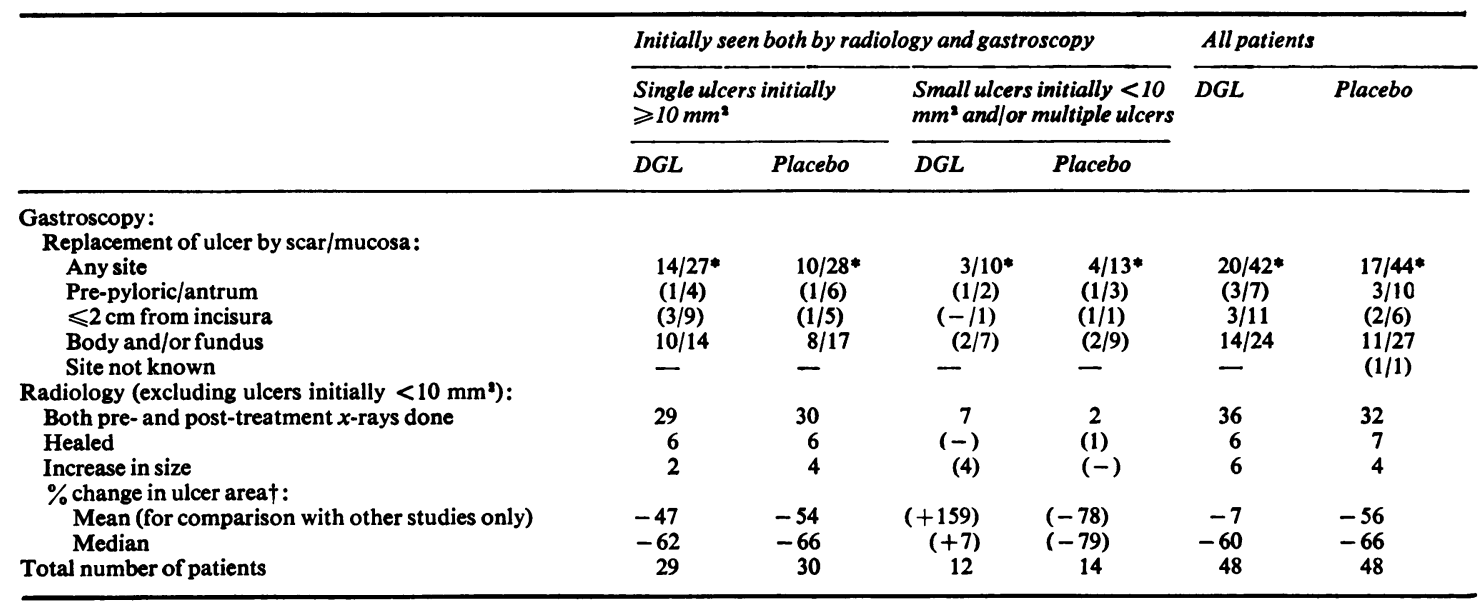

Number of patients, unless stated; indices based on fewer than 10 patients shown in parentheses.

*No. with both pre- and post-treatment assessments by gastroscopy.

$\dagger$ In calculating mean $\%$ change and median $\%$ change, increases are counted as positive, reductions as negative.

Table 4 Symptomatic changes and antacid consumption

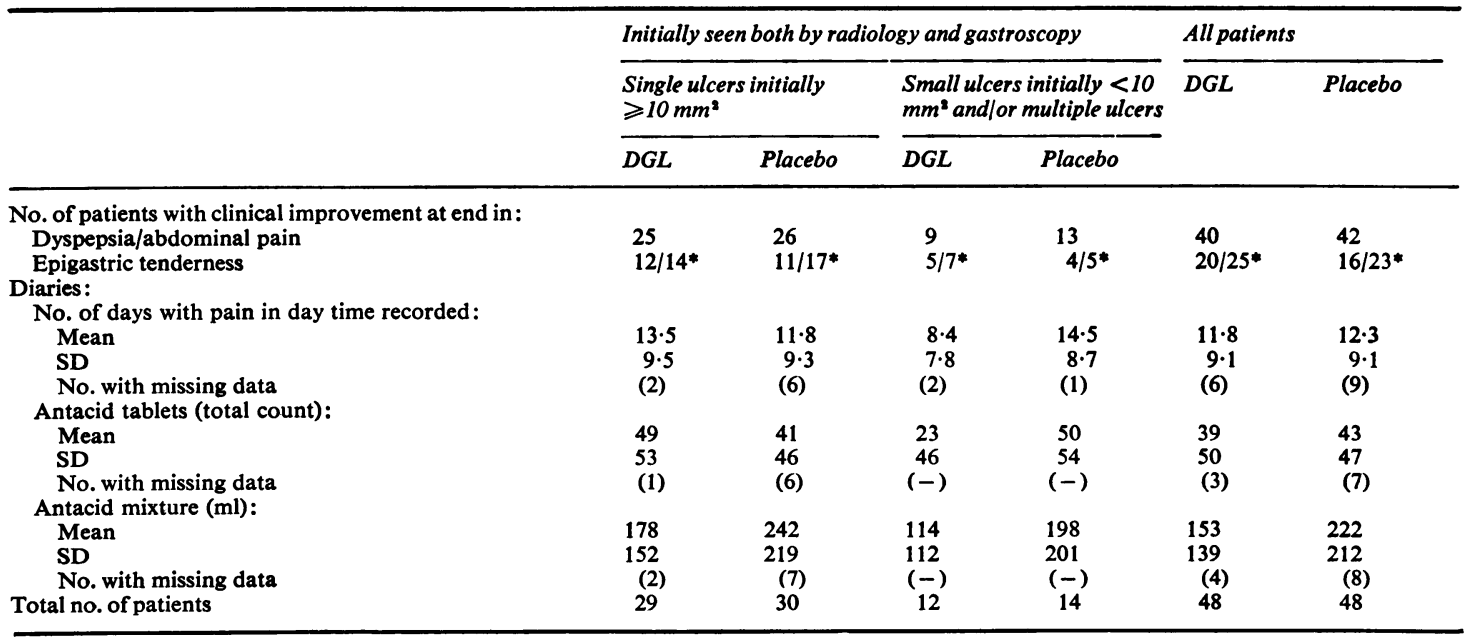

*No. with epigastric tenderness initially. 
gain was only $0.3 \mathrm{~kg}$. The same patient had previously become oedematous while taking carbenoxolone sodium. With this exception, no abnormality occurred in any of the biochemical and haematological indices measured; in particular, hypokalaemia was not recorded.

\section{Discussion}

Previously published trials of DGL have used radiological criteria alone in determining ulcer healing. In this trial both methods of assessment agreed in their failure to demonstrate therapeutic benefit, although there was substantial disagreement in their assessment of ulcer healing in individual cases. Treatment and placebo groups were similar in all respects that might be expected to influence healing, most particularly in smoking habits. Engqvist et al. (1973) have suggested that ulcers at the angulus heal less well than those at other sites. Our results show poorer healing of ulcers either at or distal to the angulus, but it is clear from Table 4 that there is no difference in healing rates between the treatment groups, even when the site of ulcer is taken into account.

The previous trials claiming benefit need careful scrutiny to explain their different conclusion. The two trials reported in 1968 are inadequate in size and in data on comparability (Table 1). The placebo group of Turpie et al. (1969) is remarkable as only one of 17 ulcers healed, and the advantage of DGL in the trial of Montgomery and Cookson (1972) was not statistically significant. None refers to how ulcers which increase in size were dealt with.

All DGL used in our own and previous trials was prepared by the same manufacturer and, although in all other trials the DGL was in the form of Caved-S, a preparation which also contains bismuth subnitrate and other antacids, we think it unlikely that any difference in formulation explains the apparent therapeutic failure in the present trial.

Can we firmly conclude that deglycyrrhizinised liquorice has no therapeutic activity? This trial was designed to be capable of detecting a doubling of the assumed placebo healing rate of around $30 \%$. Between 40 and 45 patients per treatment group were required to have only $20 \%$ chance of failing to detect any such doubling of healing rate, which would be significant at the $5 \%$ level (Clark and Downie, 1966); to reduce to $5 \%$ the chance of failing to detect it around 70 patients per treatment group would be required. The total study here had 48 patients per treatment group and it is therefore unlikely that DGL produces the doubling of the placebo healing rate which would justify its continuing place in clinical practice.

We thank our colleagues who referred patients for study, and Boehringer Ingelheim for the supply of Ulcedal and placebo capsules. We are particularly grateful to $\mathrm{Mr}$ G. R. Weeks, pharmacist of the Hallamshire Hospital, who organised both the dispensing of treatment and counting of returned drugs.

\section{References}

Bardhan, K. D., Cumberland, D. C., Dixon, R. A., and Holdsworth, C. D. A comparison of radiology and gastroscopy in the assessment of gastric ulcer healing. (In preparation.)

Clark, C. J., and Downie, C. C. (1966). A method for the rapid determination of the number of patients to include in a controlled clinical trial. Lancet, 2, 1357-1358.

Engqvist, A., Feilitzen, F. von, Pyk, E., and Reichard, H. (1973). Double-blind trial of deglycyrrhizinated liquorice in gastric ulcer. Gut, 14, 711-715.

Montgomery, R. D., and Cookson, J. B. (1972). The treatment of gastric ulcer. Comparative trial of carbenoxolone and a deglycyrrhizinated liquorice preparation (Caved-S). Clinical Trials Journal, 9, 33-36.

Russell, R. I., and Dickie, J. E. N. (1968). Clinical trial of a deglycyrrhizinised liquorice preparation in peptic ulcer. Journal of Therapeutics and Clinical Research, 2, 2-5.

Tewari, S. N., and Trembalowicz, F. C. (1968). Some experience with deglycyrrhizinated liquorice in the treatment of gastric and duodenal ulcers with special reference to its spasmolytic effect. Gut, 9, 48-51.

Turpie, A. G. G., Runcie, J., and Thomson, T. J. (1969). Clinical trial of deglycyrrhizinised liquorice in gastric ulcer. Gut, 10, 299-302. 